\title{
The 2004 Olympic Games: physiotherapy services in the Olympic Village polyclinic
}

\section{Spyridon Athanasopoulos, Eleni Kapreli, Aikaterini Tsakoniti, Konstantinos Karatsolis, Konstantinos Diamantopoulos, Konstantinos Kalampakas, Demetrios G Pyrros, Costas Parisis, Nikolaos Strimpakos}

Br J Sports Med 2007;41:603-609. doi: 10.1136/bjsm.2007.035204

See end of article for authors' affiliations

......................

Correspondence to: Dr E Kapreli, TEl Lamias, Department of

Physiotherapy, 3rd Km Old

National Road Lamia-

Athens, Lamia, 35100

Greece; ekapreli@teilam.gr

Accepted 19 April 2007

Published Online First

14 May 2007 ustained during the 2004 Olympic Games in a sample of patients Objective: First, to document the injuries sustained during the 2004 Olympic Games in a sample of patients
visiting the physiotherapy department of the Olympic Village polyclinic. Second, to provide information and data about the physiotherapy services for planning future Olympics and other mass gatherings.

Design: Observational study.

Setting: Olympic Village polyclinic.

Participants: 457 patients aged 15-72 years visited the physiotherapy department from 30 July through 30 August.

Results: The department's workload was at a peak during the last 15 days of the Olympic Games (periods B and C). The most common injuries were overuse injuries $(47.3 \%)$. The most common pathology for physiotherapy attendance was myofascial pain/muscle spasm (32.5\%), followed by tendinopathy (19.2\%) and ligament sprain (18.7\%). The most prevalent site of injury was the thigh (21\%), followed by the knee $(14.1 \%)$ and the lumbar spine (13.5\%). Most injuries had symptoms of $<7$ days' duration. The geographical region with the greatest demand for physiotherapy services was Africa (40.6\%). Most patients were athletes (74.8\%), although team officials accounted for a considerable number (14\%).

Conclusions: The smallest national teams-especially those from developing countries-were more likely to take advantage of services, probably because the larger teams had their own medical and physiotherapy staff. The characteristics of patients, their sustained injuries and the subsequent treatment varied by the accreditation status of the patients. The physiotherapy department's workload was dependent on the Olympic Games schedule.
W hereas Galen was treating the winners of Olympic events, the so called "dark Olympic victors", aiming to relieve pain and swelling, ${ }^{1}$ the Olympic Village polyclinic in Athens 2004 was offering medical services to athletes and non-athletes, winners and non-winners, under the esprit de corps, at a time when the Olympic Games returned to their homeland.

Mass gatherings require the provision of medical services for large numbers of people under unusual circumstances. Mass gatherings, including planned sports events, air shows, rock concerts, outdoor celebrations and visits by dignitaries, vary in their complexity and demand for medical services. ${ }^{2}{ }^{2}$ The 2004 Olympic Games was held in Athens from 11 to 29 August 2004 and it posed unique challenges for ensuring the public health and medical safety of people involved. ${ }^{4}$ It was the largest sporting event ever to take place in Greece, involving 11099 competitors from 202 countries, accompanied by 5501 mission members. The official organiser, Athens 2004 Organising Committee for the Olympic Games, was responsible for providing health services at all Olympic residential, training and competition sites. The main venue for medical services provision was the polyclinic, located in the Olympic Village. One of the most popular support services of the polyclinic was the physiotherapy department, providing treatment for athletes, the Olympic family and the staff working or residing in the Olympic Village.

At present, there are limited research data concerning the epidemiology of injuries and related medical issues during the Olympic Games or any other analogous mass sports tournaments. ${ }^{5-10}$ For the Olympic polyclinic, and more specifically the physiotherapy services, no other previous comprehensive data report was found mentioning variables associated with the facilities and organisation of the department, concerns about the patients (workload, special needs, etc) or the nature of injuries requiring treatment.

The purpose of the current study was therefore to (a) document the injuries sustained in the patients visiting the physiotherapy department at the polyclinic and $(b)$ provide information about the physiotherapy service in the polyclinic, supplying data for planning future Olympics and other mass gatherings.

\section{PATIENTS AND METHODS \\ Participants}

The patients were categorised on the basis of their accreditation status: athletes (persons taking part in competition), team officials (eg, coaches and trainers), the Olympic family (including members of the International Olympic Committee (IOC), National Olympic Committee and other dignitaries), workforce and volunteers. The physiotherapy service procedure and data collection were approved by the Athens 2004 Medical Service Committee for the Olympic Games. All patients participated in the study as part of the Participation Agreement and provided written consent before receiving physiotherapy treatment.

\section{Physiotherapy service organisation}

The physiotherapy department was a $1000 \mathrm{~m}^{2}$ facility offering service during the 1 month of operation of the Olympic Village from 30 July to 30 August. It was open 16 hours a day, 


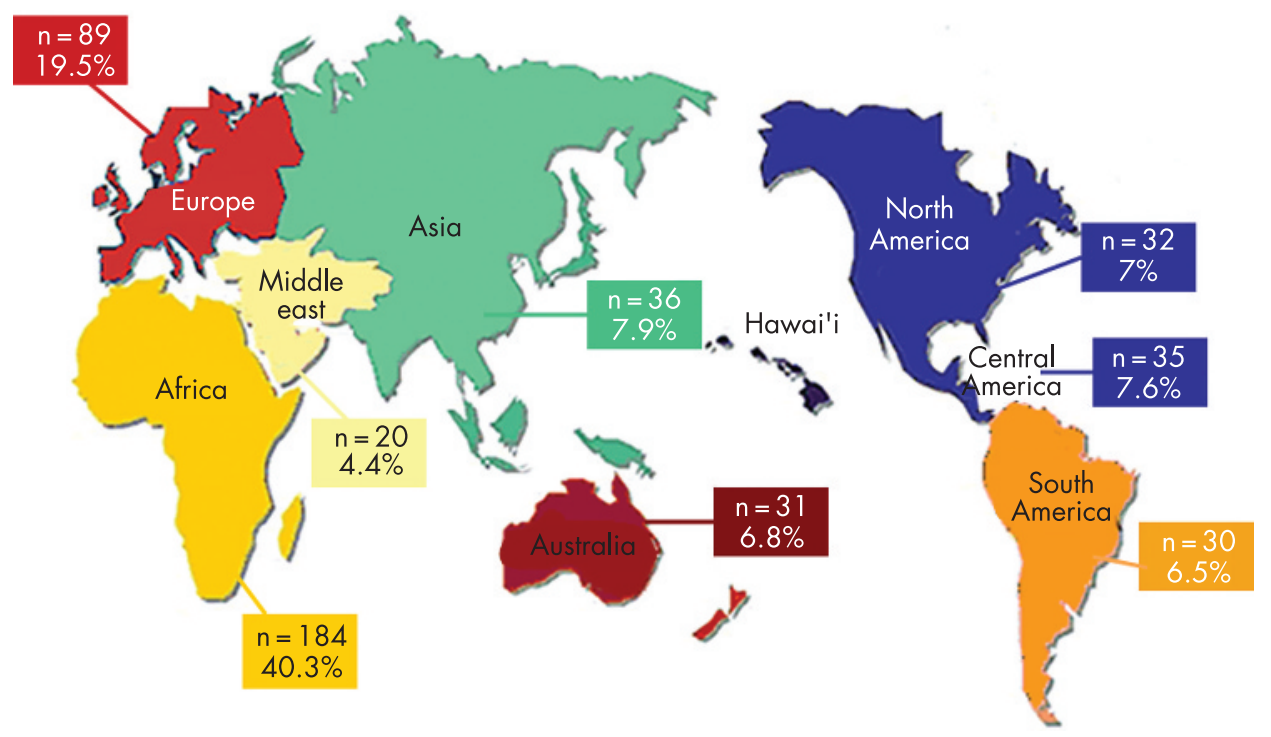

Figure 1 Percentages of patients from different geographical regions. Note that Central America is included with the Caribbean on the map.

consisting of a reception-waiting area, two examination rooms, a gym, a hydrotherapy unit with a therapeutic pool, a clinical unit with 12 therapy rooms, sauna and changing rooms-toilets. The department provided treatment mainly for trauma cases and injuries. Other facilities also offered prophylactic massage to the athletes in the Olympic Village, but these were outside the polyclinic and physiotherapy department. There was a special arrangement for these facilities and the staff there were specialists in athletic massage, but not physiotherapists.

Seventy-three physiotherapists (51 men, 22 women), all volunteers (46 Greek, 10 British, 9 Australian, 3 Swiss, 2 Cypriot, I Italian, I German and I Spanish) worked in the physiotherapy department. Nineteen (26\%) of the staff had a postgraduate degree (MSc or $\mathrm{PhD}$ ) and $18(24.6 \%)$ had previous experience in sports tournaments. During the entire operating period, $22( \pm 6)$ physiotherapists were offering services in two separate shifts (morning/afternoon). It was a prerequisite that each volunteer physiotherapist had to offer her/his services for at least 10 days. The physiotherapy staff had a venue director and two venue subdirectors. In addition to the physiotherapists, a four-member secretarial staff worked in the department, who were responsible for booking appointments, collecting physiotherapy encounter forms and sending them to a central location of the polyclinic.

Physiotherapy care at the polyclinic was provided free of charge to the patient after medical referral. Athletes had to be accompanied by a member of their national medical personnel or their own trainer. The patients were assessed during their first visit to the department. A SOAP (Subjective, Objective, Assessment, Plan) assessment form and a treatment form were completed in English. All physiotherapists had a training session on completing the forms so that a standard procedure was followed. After the initial assessment, the patient received treatment immediately. Data from physiotherapy assessment and treatment forms were entered into a computer and daily reports were generated.

As in previous Olympic Games (Seoul, Barcelona, Atlanta) the operations in the polyclinic began 14 days before the opening ceremony and extended for 2 days after the closing ceremony. The entire period ( 30 days) of data collection was divided into three parts: period A-30 July to 8 August; period B-9 August to 18 August and period C-19 August to 30 August. The periods of data collection were categorised so that the influence of the Games participation volume on the admission in the physiotherapy clinic could be examined.

\section{Data management and statistical analysis}

All data were compiled by the venue director, SA. The data were divided into $(a)$ three groups based on the accreditation status (total, athletes and non-athletes) and $(b)$ three groups based on the period (period A, period B and period $\mathrm{C}$ ), and descriptive statistics were calculated. The analysis was performed in SPSS, version 11.5 for Windows (Lead Technologies Inc SPSS Inc, Chicago, Illinois, USA).

\section{RESULTS \\ Patients}

From 30 July to 30 August, 457 people visited the physiotherapy department and had an assessment form completed. Most patients were athletes $(n=342,74.8 \%)$, followed by team officials $(n=64,14 \%)$, workforce $(n=36,7.9 \%)$, IOC members $(\mathrm{n}=10,2.2 \%)$ and volunteers $(\mathrm{n}=5,1.1 \%)$. Demand for physiotherapy was highest from Africa, followed by Europe, Asia and others (fig l). The characteristics of patients who received physiotherapy care varied according to their accreditation status (table 1).

Table 1 Demographic data of patients

\begin{tabular}{llll}
\hline $\begin{array}{l}\text { Patients } \\
\text { Mean (SD) \{range }\end{array}$ & \multicolumn{1}{c}{$\begin{array}{c}\text { Age } \\
\text { Mean (SD) }\{\text { range }\end{array}$} & $\begin{array}{l}\text { Women } \\
\text { No (\%) }\end{array}$ & $\begin{array}{l}\text { Men } \\
\text { No (\%) }\end{array}$ \\
\hline $\begin{array}{l}\text { Athletes }(n=342) \\
\text { Non-athletes }(n=115)\end{array}$ & $25.4(5.1)\{15-44\}$ & $147(43)$ & $195(57)$ \\
Total $(n=457)$ & $42.7(12.7)\{18-72\}$ & $37(32.2)$ & $78(67.8)$ \\
\hline
\end{tabular}




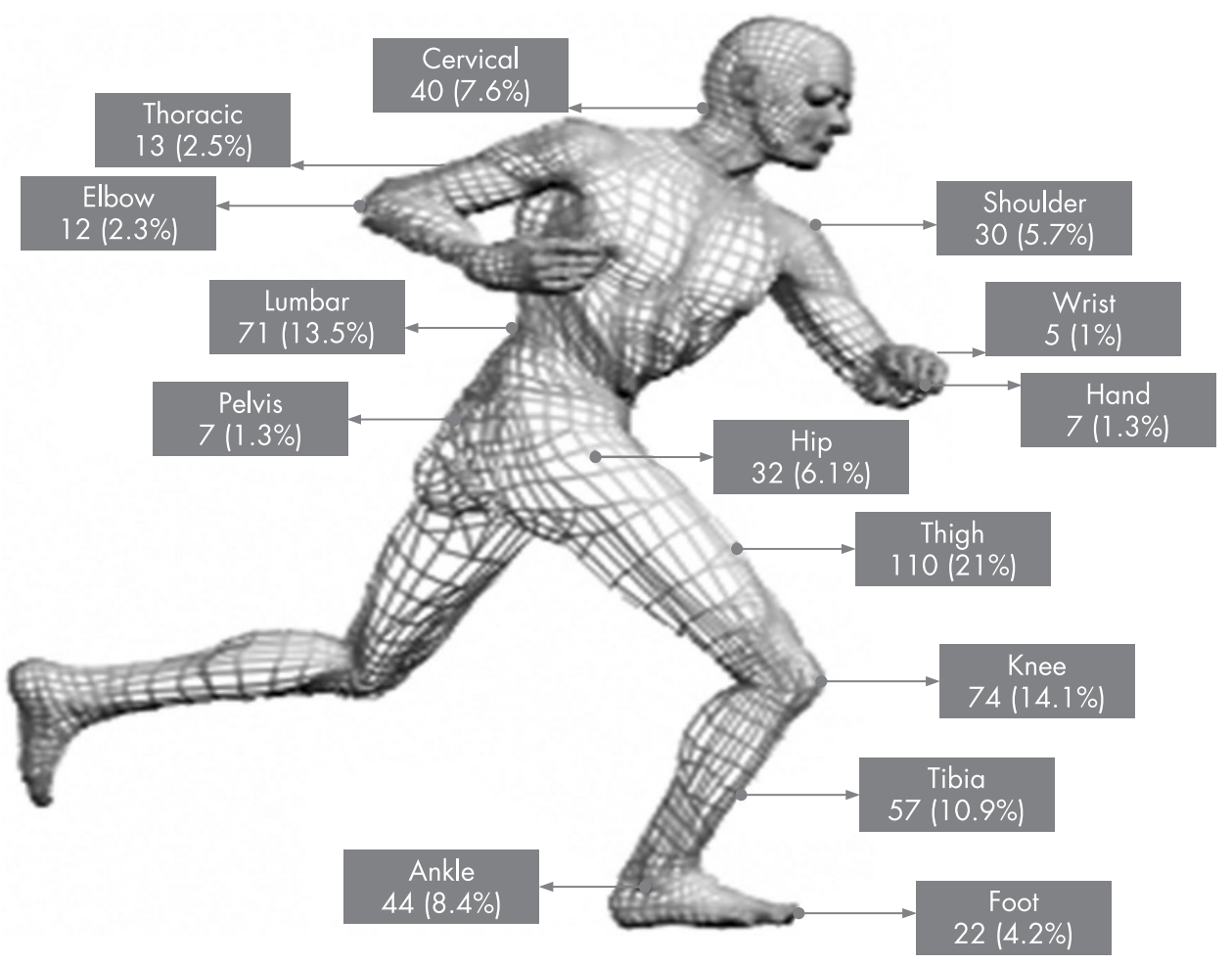

\section{Injuries}

\section{Overal}

Most injuries were overuse injuries ( $n=216,47.3 \%$ ), followed by acute $(n=158,34.6 \%)$ and chronic injuries $(n=105$,
Figure 2 Percentages of injuries by anatomical location.

Table 2 An overview of the nature of injuries in all the patients, athletes and non-athletes

\begin{tabular}{|c|c|c|c|}
\hline & $\begin{array}{c}\text { Total }(n=524) \\
\text { No (\%) }\end{array}$ & $\begin{array}{c}\text { Athletes }(n=398) \\
\text { No }(\%)\end{array}$ & $\begin{array}{c}\text { Non-athletes }(n=126) \\
\text { No }(\%)\end{array}$ \\
\hline \multicolumn{4}{|l|}{ Site of injury } \\
\hline Cervical spine & $40(7.6)$ & $13(3.3)$ & $27(21.4)$ \\
\hline Thoracic spine & $13(2.5)$ & $9(2.3)$ & $4(3.2)$ \\
\hline Shoulder & $30(5.7)$ & $20(5)$ & $10(7.9)$ \\
\hline Elbow & $12(2.3)$ & $8(2)$ & $4(3.2)$ \\
\hline Hand & $7(1.3)$ & $6(1.5)$ & $1(0.8)$ \\
\hline Wrist & $5(1.0)$ & $2(0.5)$ & $3(2.4)$ \\
\hline Pelvis & $7(1.3)$ & $6(1.5)$ & $1(0.8)$ \\
\hline Lumbar spine & 71 (13.5) & $41(10.3)$ & $30(23.8)$ \\
\hline Hip & $32(6.1)$ & $28(7)$ & $4(3.2)$ \\
\hline Thigh & $110(21)$ & $109(27.4)$ & $1(0.8)$ \\
\hline Knee & $74(14.1)$ & 49 (12.3) & 25 (19.8) \\
\hline Lower leg & $57(10.9)$ & $54(13.6)$ & $3(2.4)$ \\
\hline Ankle & $44(8.4)$ & $37(9.3)$ & $7(5.6)$ \\
\hline Foot & $22(4.2)$ & $16(4)$ & $6(4.8)$ \\
\hline Injuries by pathology & $(n=406)$ & $(n=302)$ & $(n=104)$ \\
\hline Ligament sprain & $76(18.7)$ & $56(18.5)$ & $20(19.2)$ \\
\hline Muscle strain & 70 (17.2) & $68(22.5)$ & $2(1.9)$ \\
\hline Contusion/haematoma & $10(2.5)$ & $10(3.3)$ & 0 \\
\hline Tendinopathy & 78 (19.2) & 59 (19.5) & $19(18.3)$ \\
\hline Fracture/stress fracture & $4(1)$ & $2(0.7)$ & $2(1.9)$ \\
\hline Dislocation & $3(0.7)$ & $2(0.7)$ & $1(1)$ \\
\hline Root compression & $41(10.1)$ & $21(7)$ & 20 (19.2) \\
\hline Facet syndrome & $9(2.2)$ & $6(2)$ & $3(2.9)$ \\
\hline Cartilage lesion & $6(1.5)$ & $2(0.7)$ & $4(3.8)$ \\
\hline Plantar fasciitis & $18(4.4)$ & $13(4.3)$ & $5(4.8)$ \\
\hline Arthritis & $25(6.2)$ & $2(0.7)$ & $23(22.1)$ \\
\hline Myofascial pain/muscle spasm & $132(32.5)$ & $110(36.4)$ & $22(21.2)$ \\
\hline Spina bifidus & $3(0.7)$ & $1(0.3)$ & $2(1.9)$ \\
\hline Shin splints & $3(0.7)$ & $3(1)$ & 0 \\
\hline Compartment syndrome & $4(1)$ & $3(1)$ & $1(1)$ \\
\hline
\end{tabular}




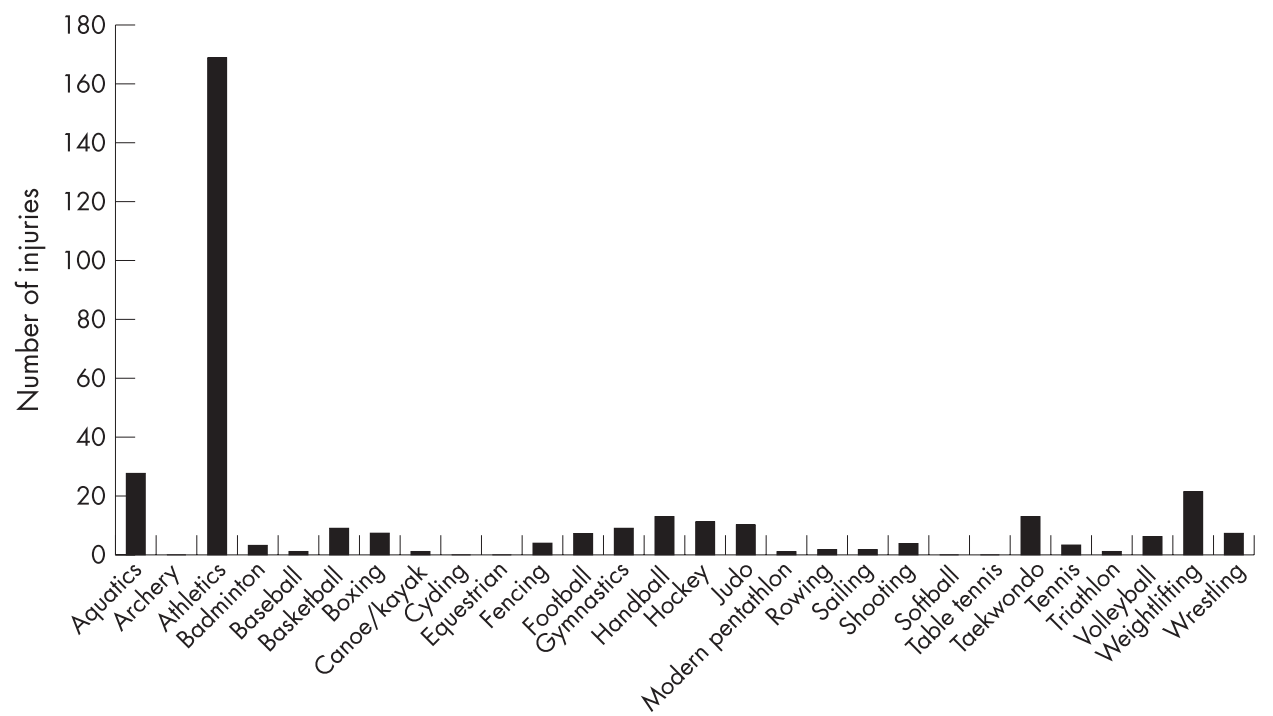

Figure 3 Total number of injuries in different sports.

lumbar spine and the lower leg (table 2, fig 2). Most injuries had symptoms of $<7$ days' duration ( $\mathrm{n}=377,82.5 \%$ ), whereas a smaller percentage accounted for a duration of 7-29 days $(\mathrm{n}=78,17.1 \%)$ or a duration of more than 30 days $(\mathrm{n}=2$, $0.4 \%)$.

\section{Athletes}

In the athletes' group, there was also a prevalence of overuse injuries $(n=188,55 \%)$, followed by acute $(n=135,39.5 \%)$ and chronic injuries $(n=34,9.9 \%)$. The majority of injured athletes were from athletics $(\mathrm{n}=169,51.1 \%)$, followed by aquatics $(\mathrm{n}=28,8.4 \%)$ and weightlifting $(\mathrm{n}=21,6.3 \%) \quad($ fig 3$)$. Myofascial pain/muscle spasm was the most common pathology, followed by muscle strain, tendinopathy and ligament sprain (table 2). The most widespread sites of injury were the thigh, the lower leg, the knee and the lumbar spine (table 2). Most athletes presented with symptoms of $<7$ days' duration $(\mathrm{n}=286,83.6 \%)$, whereas a smaller percentage presented with symptoms of $7-29$ days $(n=55,16.1 \%)$ or $>30$ days $(\mathrm{n}=1,0.3 \%)$. Most injuries occurred during training $(\mathrm{n}=279$, $81.6 \%)$ with the remainder during competition $(n=41,12 \%)$, non-athletic activities $(\mathrm{n}=10,2.9 \%)$ or warming-up $(\mathrm{n}=3$, $0.9 \%)$.

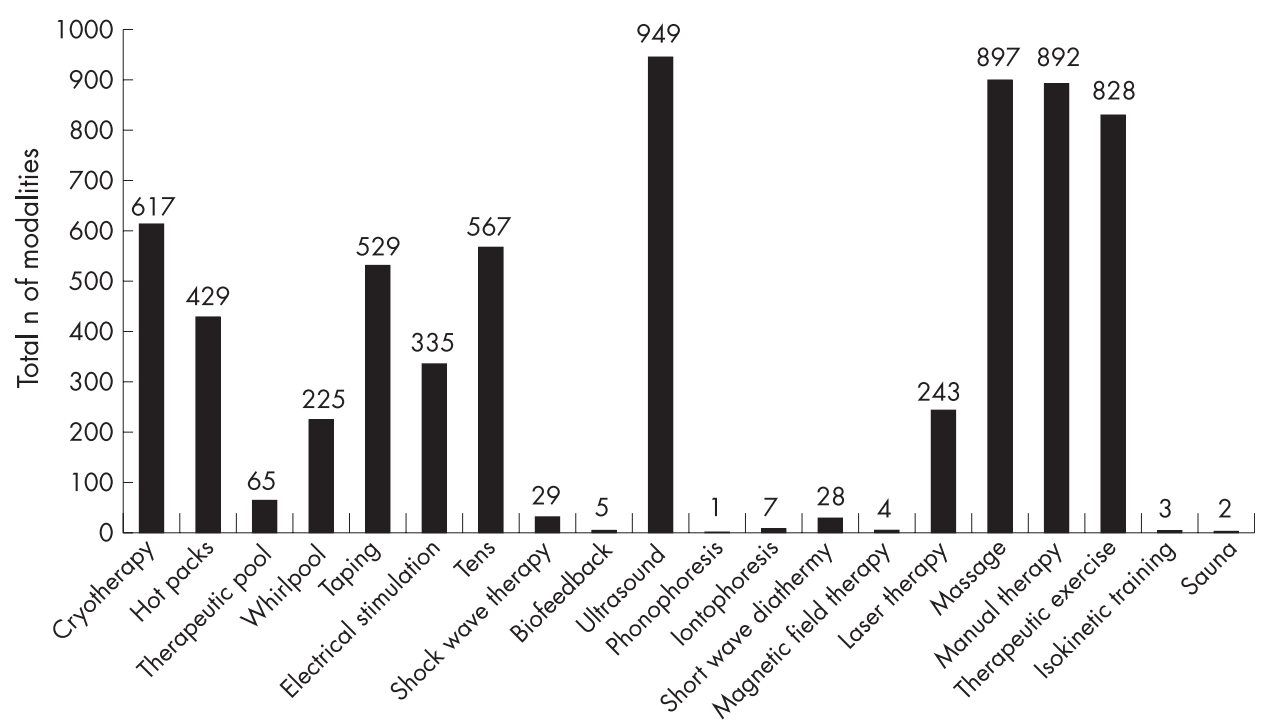

\section{Non- athletes}

Non-athletes, surprisingly, had mainly chronic injuries $(n=71$, $58.2 \%)$ and had a smaller incidence of overuse $(n=28,22.9 \%)$ and acute injuries $(n=23,18.9 \%)$. Moreover, arthritis was the condition most often needing physiotherapy, followed by myofascial pain/muscle spasm, root compression and ligament sprain (table 2). The lumbar spine, cervical spine and the knee, were the commonest sites of injury (table 2 ). Most non-athletes presented symptoms of $<7$ days $(n=91,79.1 \%)$, whereas a smaller percentage was accounted for a duration of 7-29 days $(\mathrm{n}=23,20 \%)$ or a duration of $>30$ days $(\mathrm{n}=1,0.9 \%)$.

\section{Treatment}

Overall, the mean (SD) treatment sessions were 4.4 (4), range 1-44. The majority of patients (54\%) had fewer than three sessions, and only $6 \%$ had more than 10 sessions. A considerable percentage of patients $(28 \%)$ came to the physiotherapy department only once, in order to be assessed and had one session of treatment, mainly consultation. The treatment modalities that were mostly used were in order ultrasound, massage, manual therapy techniques and others (fig 4). The total number of modalities used differed among the three periods: the period with the highest modalities usage was

Figure 4 Use of different modalities. 


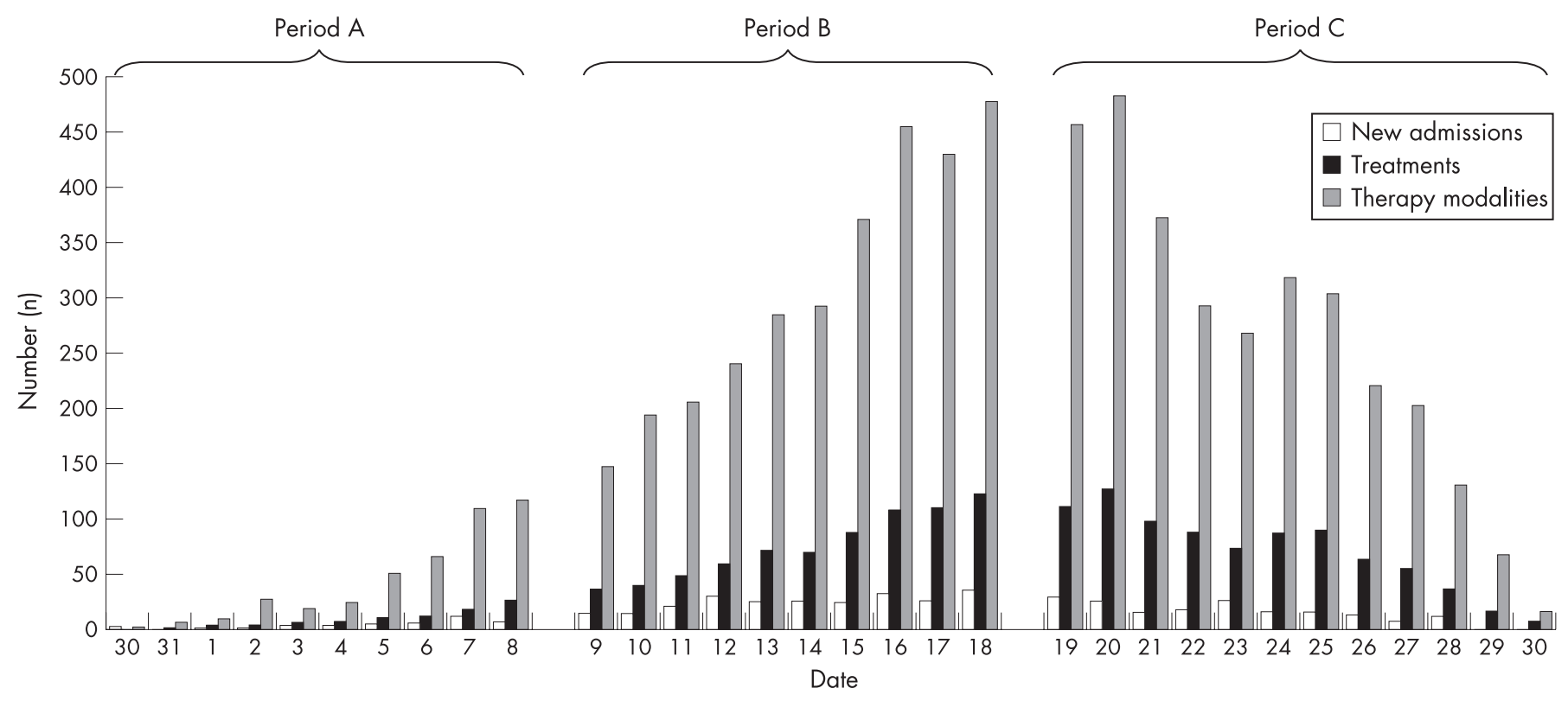

Figure 5 Number of new admissions, patients treated per day and total number of modalities during the three periods of the department operation.

period C $(\mathrm{n}=3138,47.2 \%)$, followed by period B $(\mathrm{n}=3092$, $46.5 \%)$ and period $\mathrm{A}(\mathrm{n}=425,6.4 \%)$ (fig 5$)$.

More than half of the new admissions took place during period B $(n=243,53.2 \%)$, followed by period C $(n=177$, $38.7 \%)$ then period $\mathrm{A}(\mathrm{n}=37,8.1 \%)$ (fig 5$)$. Nevertheless, period $\mathrm{C}$ experienced the highest number of patients treated in total $(\mathrm{n}=848,50.1 \%)$, followed by period $\mathrm{B}(\mathrm{n}=757,44.7 \%)$ and period A $(n=89,5.3 \%)$. However, the physiotherapy department's busiest period from patients' visits per day was period B (mean (SD) 75.7 (31.0), range 35-123), then period C (70.7 (37.8), range 5-127) and, finally, period A (8.9 (8.8), range $1-28$ ) (fig 5).

\section{DISCUSSION}

As far as we know, this is the first study presenting information about physiotherapy services at a mass gathering event such as the Olympic Games. The immense participation and the sheer volume of people involved in the Olympic Games pose significant challenges to the medical community and require considerable planning by healthcare services. However, there is a distinct variation in the provision of medical care, often with poor documentation and records.

Planning for physiotherapy services at the Olympics 2004 began 4 years before the Games. The limited availability of published data about such events made valid planning extremely difficult. The physiotherapy director and officials of the medical team met the physiotherapy director of the Sydney 2000 Olympic Games to gain from his experience and knowledge. The information provided included the number of patients a day, the shifts and the number of physiotherapists needed. However, a number of unknown problems may be critical, such as the type of injuries treated and the different modalities needed. It is important to create a standardised, yet detailed, report by an international specialised committee (for all areas within the polyclinic) that will provide the next country with reliable information to help them to plan and organise efficiently.

The number of patient admissions varied according to their country. The geographical region with the greatest demand for physiotherapy services was Africa, followed by Europe and Asia. Similarly, with previous sports gathering events, it was the smallest national teams-especially those from developing countries-who needed to take advantage of services, probably because the larger teams were escorted by their own medical and physiotherapy staff. ${ }^{10}$ Furthermore, we believe that athletes from some of the large teams were initially prohibited from using local medical services for fear that the treatment might be inadequate and subsequently lead to a positive doping control test. Although the number of interpreters was adequate, in general, there was an increased demand for Arabic speaking interpreters as a considerable number of patients were from Middle Eastern and Arabic speaking African countries.

Seventy-three people volunteered as physiotherapists during the period of the Olympic Games at the polyclinic physiotherapy department. A considerable percentage of the staff had undertaken postgraduate studies or had previous experience in sports injuries, which enhanced the overall capability of the staff. We suggest that for future planning, all volunteers participating in the polyclinic physiotherapy department should be required to have a verified specialisation in sports rehabilitation, probably by official membership of a sports physiotherapy association, which would improve the standards of service. To overcome previously mentioned problems, ${ }^{6}$ it was proposed that each physiotherapist must offer their services at the venue for at least 10 days. This regulation ensured that personnel would not vary from day to day, that sufficient staff would be available during all three periods and that communication would be effective.

It is worth mentioning that the success of physiotherapy services was mainly based on the motivation and job satisfaction of the volunteers, a complex and unique process previously described as "enlightened self-interest", attributed only to polyclinic volunteers. ${ }^{11}$ Future organisers could benefit by selecting appropriately motivated volunteer personnel and creating rewarding work environments for them. Although there were more male than female patients, as in previous reports, ${ }^{9}$ there was some difficulty during some shifts in finding female physiotherapists to treat female Muslim patients. The male predominance of the physiotherapy staff was a disadvantage in the running of the department; and therefore, this should be taken into account in future planning.

The characteristics of patients, the nature of their injuries and the treatment given varied by patients' accreditation status. This variability reflects mainly the different age, level of activity 


\section{What is already known on this topic}

The enormous participation and the sheer volume of people involved in the Olympic Games pose significant challenges to the medical community and require considerable planning by healthcare services.

\section{What this study adds}

- It provides a detailed documentation of the injuries sustained during the 2004 Olympic Games in a sample of patients visiting the physiotherapy department at the polyclinic.

- Information about the physiotherapy services is given, supplying data and suggestions for planning future Olympics and other mass gatherings.

and exposures that each group experienced. Although the physiotherapy department in the polyclinic was prepared for the provision of care for patients, mainly athletes with acute injuries, there was also a large proportion of patients (nonathletes) with chronic injuries and diseases. It was interesting to note that although most of the injuries in non-athletes were chronic injuries such as arthritis, symptoms referred to had an onset of $<7$ days. It has previously been mentioned that nonathletes (team official and IOC members) take advantage of the opportunity to receive free medical services ${ }^{12}$ or to obtain free eyeglasses or dental fillings during Olympic Games; this has been considered the host city's obligation. ${ }^{6}$ The IOC Medical Commission probably needs to examine this problem and if it is considered that Olympic "family" members exploit the situation, then new regulations may be appropriate.

In athletes, most injuries were overuse and acute injuries, with a predominance of overuse injuries. The lower limb was the most affected part of the body, in accordance with previous results. ${ }^{13-15}$ Furthermore, most injured athletes were from the disciplines of athletics and aquatics. Most visits were for minor injuries and were resolved within few sessions or only with consultation. However, some patients had severe injuries or conditions that required an extensive number of sessions. It has to be mentioned that some patients had double sessions of treatment in one day either because of a complex pathological situation or because of the severity of the injury in combination with the restricted available period of treatment (depending on the competition schedule).

The physiotherapy department's workload was dependent on the operation period that complied with the Olympic Games schedule. ${ }^{9}$ From 30 July until 8 August, only a limited number of treatment sessions were provided. That period was a preparatory period for both athletes and workforce, giving the opportunity for modalities and facilities testing. From 9 to 18 August, the number of treatment sessions and the number of new admissions increased considerably. During this period, according to the official schedule, competition in most sports had started, and all teams had arrived in the Olympic Village as the opening ceremony was held on 13 of August. The workload of the department was at its highest between 19 and 30 August. Athletics started on 18 August and most sports had their finals during the last days of this period, implying increased intensive competition, which may have accounted for the increased number of competitors needing physiotherapy during this period.
Use of the modalities followed a similar pattern to the department's workload. As previously mentioned, ${ }^{16}$ the most commonly used treatments were ultrasound, massage, manual therapy techniques, therapeutic exercise, cryotherapy, taping and tens. It is suggested that multifunctional equipment should be used, including ultrasound, electric stimulation and laser, one for each therapy room, thus ensuring adequate provision. Because of the greater number of overuse and acute injuries, diathermy and hot pads were not needed in such quantity, mainly being used in cases of chronic injury and disease. In contrast, the acquisition of an ice machine proved crucial, as it was extremely difficult otherwise to provide cryotherapy and cold whirlpool for such a demanding workload. There was substantial cooperation with other services of the polyclinic, especially with podiatrists. Patients with mainly overuse injuries were referred for assessment and to obtain orthotics as a part of their therapeutic process.

In conclusion, it is important for planning medical and physiotherapy services in future large sports events such as the Olympic Games that adequate data from previous similar events to be supplied. This paper provides information about the physiotherapy services in the polyclinic during the 2004 Olympic Games in Athens. The characteristics of patients, their sustained injuries and their treatment varied according to their accreditation status. Organisers of future Olympics need to take into account that patients in a polyclinic physiotherapy department are not only athletes with acute or overuse injuries but also non-athletes, often with chronic diseases. Lastly, the physiotherapy department's workload was dependent on the Olympic Games schedule, which also has to be considered for proper planning.

\section{ACKNOWLEDGEMENTS}

The professionalism and support of the participating polyclinic physiotherapists is gratefully acknowledged.

\section{CONTRIBUTORS}

SA, the venue director of the physiotherapy department suggested this article, supervised the data collection, data analysis and preparation of the manuscript. EK, reviewed the literature review, analysed the data and prepared the manuscript. AT and KK were responsible for the data collection. $\mathrm{KD}$ and $\mathrm{KK}$, venue subdirectors of the physiotherapy department, assisted in the recruitment and screening of participants. DGP, the Olympic Village polyclinic manager, supervised the project and reviewed the manuscript. CP, chief medical officer of Athens 2004 Organising Committee for the Olympic Games, supervised the project. NS assisted in the study design, data collection and analysis and reviewed the manuscript.

\section{Authors' affiliations}

Spyridon Athanasopoulos, Aikaterini Tsakoniti, Konstantinos Karatsolis, National and Kapodistrian University of Athens, Faculty of Physical Education and Sport Science, Greece

Eleni Kapreli, Nikolaos Strimpakos, TEI Lamias, Department of Physiotherapy, Greece

Konstantinos Diamantopoulos, Konstantinos Kalampakas, Physiopraxis Clinic, Greece

Demetrios G Pyrros, National Centre of Emergency Care, Greece

Costas Parisis, General Hospital of Ag. Paulos, Greece

Conflict of interest: None declared

\section{REFERENCES}

1 Bartels EM, Swaddling J, Harrison AP. An ancient Greek pain remedy for athletes. Pain Pract 2006;6:212-8.

2 Grange JT. Planning for large events. Curr Sports Med Rep 2002;1:156-61.

3 De Lorenzo RA. Mass gathering medicine: a review. Prehospital Disaster Med 1997; 12:68-72.

4 Hadjichristodoulou C, Mouchtouri V, Soteriades ES, et al. Mass gathering preparedness: the experience of the Athens 2004 Olympic and Para-Olympic Games. J Environ Health 2005;67:52-7. 
5 Neville VJ, Molloy J, Brooks JH, et al. Epidemiology of injuries and illnesses in America's Cup yacht racing. Br J Sports Med 2006:40:304-1 1

6 Eaton SB, Woodfin BA, Askew JL, et al. The polyclinic at the 1996 Atlanta Olympic Village. Med J Aust 1997; 167:599-602.

7 Allen TL, Jolley SJ, Cooley VJ, et al. The epidemiology of illness and injury at the alpine venues during the Salt Lake City 2002 Winter Olympic Games. J Emerg Med 2006;30:197-202

8 Best JP, Mclntosh AS, Savage TN. Rugby World Cup 2003 injury surveillance project. Br J Sports Med 2005;39:812-7.

9 Wetterhall SF, Coulombier DM, Herndon JM, et al. Medical care delivery at the 1996 Olympic Games. Centers for Disease Control and Prevention Olympics Surveillance Unit. JAMA 1998;279:1463-8.

10 Hannay DR, English BK, Usherwood TP, et al. The provision and use of medical services during the 1991 World Student Games in Sheffield. J Public Health Med 1993; 15:229-34.

11 Reeser JC, Berg RL, Rhea D, et al. Motivation and satisfaction among polyclinic volunteers at the 2002 Winter Olympic and Paralympic Games. Br J Sports Med 2005;39:e20

12 Hannay DR, English BK, Usherwood TP, et al. The provision and use of medical services during the 1991 World Student Games in Sheffield. J Public Health Med 1993; 15:229-34

13 Cassell EP, Finch CF, Stathakis VZ. Epidemiology of medically treated sport and active recreation injuries in the Latrobe Valley, Victoria, Australia. Br J Sports Med 2003:37:405-9

14 Kennedy M, Dunne C, Mulcahy B, et al. The sports' clinic: a one year review of new referrals. Ir Med J 1993;86:29-30.

15 Devereaux MD, Lachmann SM. Athletes attending a sports injury clinic-a review. Br J Sports Med 1983;17:137-42.
16 Nyland J, Nolan MF. Therapeutic modality: rehabilitation of the injured athlete. Clin Sports Med 2004;23:299-313, vii.

\section{COMMENTARY}

Physiotherapists play a key role in the treatment of athletes of all sports during an Olympic Games and the provision of physiotherapy facilities is an essential part of the organisation of any major championships. This report presents useful data concerning the personnel and facilities the host city is expected to provide during an Olympics Games. It also highlights problems which several experienced physiotherapists have observed for many years. This paper will provide helpful information for those given the exciting yet onerous task of organising physiotherapy in the Olympic village for London 2012.

Michael J Callaghan University of Manchester, UK michael.callaghan@manchester.ac.uk

\section{Stay a step ahead with Online First}

We publish all our original articles online before they appear in a print issue. This means that the latest clinical research papers go straight from acceptance to your browser, keeping you at the cutting edge of medicine. We update the site weekly so that it remains as topical as possible. Follow the Online First link on the home page and read the latest research. 